\title{
Analysis of Tokamak fusion device parameters affecting the efficiency of Tokamak operation
}

\author{
Nour El-Houda El-zmeter ${ }^{1^{*}}$, Ben Schmiga ${ }^{2}$, Alicia Murphy ${ }^{3}$, Brendan Boyd-Weetman ${ }^{4}$ \\ University of Technology Sydney, P.O Box 123, MaPS, Broadway NSW 2007. \\ 1 E-Mail: Nour.E.El-zmeter@student.uts.edu.au \\ 2 E-Mail: Benjamin.R.Schmiga@student.uts.edu.au \\ 3 E-Mail: Alicia.Murphy@student.uts.edu.au \\ 4 E-Mail: Brendan.Boyd-Weetman@student.uts.edu.au \\ * Author to whom correspondence should be addressed; \\ E-Mail: Nour.E.El-zmeter@student.uts.edu.au
}

DOI: http://dx.doi.org/10.5130/pamr.v4i0.1444

\begin{abstract}
Nuclear Power has been available as a relatively clean and reliable energy source for several decades. While tokamak engines have been in existence almost as long as successful fission-powered nuclear generators, they have not yet reached operational success for energy generation. This meta study collates key fusion device parameters and determines ideas on the applicability of fusion devices for energy. This paper supports the argument that toroidal tokamaks are not limited by volume whereas spherical designs have a potential volume limit, spherical tokamaks use a lower magnetic field current than toroidal tokamaks. Further scientific and engineering progress is required before tokamak devices can be a viable technology to be used for energy generation.
\end{abstract}

Keywords: Plasma, fusion, Tokamak, Magnetic field, plasma current, toroidal, spherical 


\section{Introduction}

Tokamak reactors are experimental power generators that use thermonuclear fusion to generate energy $[1,2]$. While progress on the technology is slow due to many factors, achieving fusion power is highly desirable because its fuel, hydrogen, is functionally limitless as hydrogen is the most plentiful element in the universe [3], it has no hazardous by-products [4, 5], and if it malfunctions, the reaction would simply destabilise and stop $[6,7]$.

Nuclear fusion was discovered to be possible in the 1930's [8], and has been heavily studied and applied in areas such as energy generation $[9,10,11]$ and weapons development $[12,13]$ with varying success. The idea that would later become the tokamak reactor was first suggested by Oleg Lavrentiev, and later made reality by Soviet physicists Igor Tamm and Andrei Sakharov in the 1950's [14].

In a tokamak reactor, the fusion reaction takes place within a steel constructed vacuum chamber $[15,16,17]$, either toroidal or spherical in design. This chamber is surrounded by magnetic coils in toroidal and poloidal configurations, which generate the magnetic field with sufficient strength to contain the plasma, the combination of the two magnetic field orientations causes an induced magnetic field in the form of a directional plasma current, maintaining the plasma flow within the magnetic field (as seen in diagram 1) and preventing collision with the outer wall [18, 19, 20]. The inside of the chamber is usually lined with a heat-resistive element, such as lead, lithium, and boron to help the chamber withstand the intense heat generated by the plasma [21, 22, 23]. Tokamak reactors use the isotopes of hydrogen, deuterium and tritium, in a fusion reaction to produce helium. $[24,25,26]$ The reaction is initiated by firing a neutron beam into the chamber to heat, and thus excite the hydrogen ions for fusion to take place, while also accelerating the particles further. [27, 28, 29] The reaction is initiated and maintained by applying immense atmospheric pressure inside the chamber, this forces the atoms together in a similar fashion as gravity in a naturally occurring fusion reaction within a star [30, $31,32]$. Continual engineering and scientific challenges that face the design of fully operational tokamaks for energy generation are extensive. Major examples include issues such as the interior coatings used are not currently able to withstand the extreme plasma temperatures for extended periods $[33,34]$, the magnetic confinement field is difficult to keep strong enough whilst still able to dynamically change with the continuous plasma reaction $[35,36]$ and the pressure inside the chamber is unstable largely for similar reasons $[37,38]$. 
Diagram 1. basic image of a toroidal tokamak reactor [14]

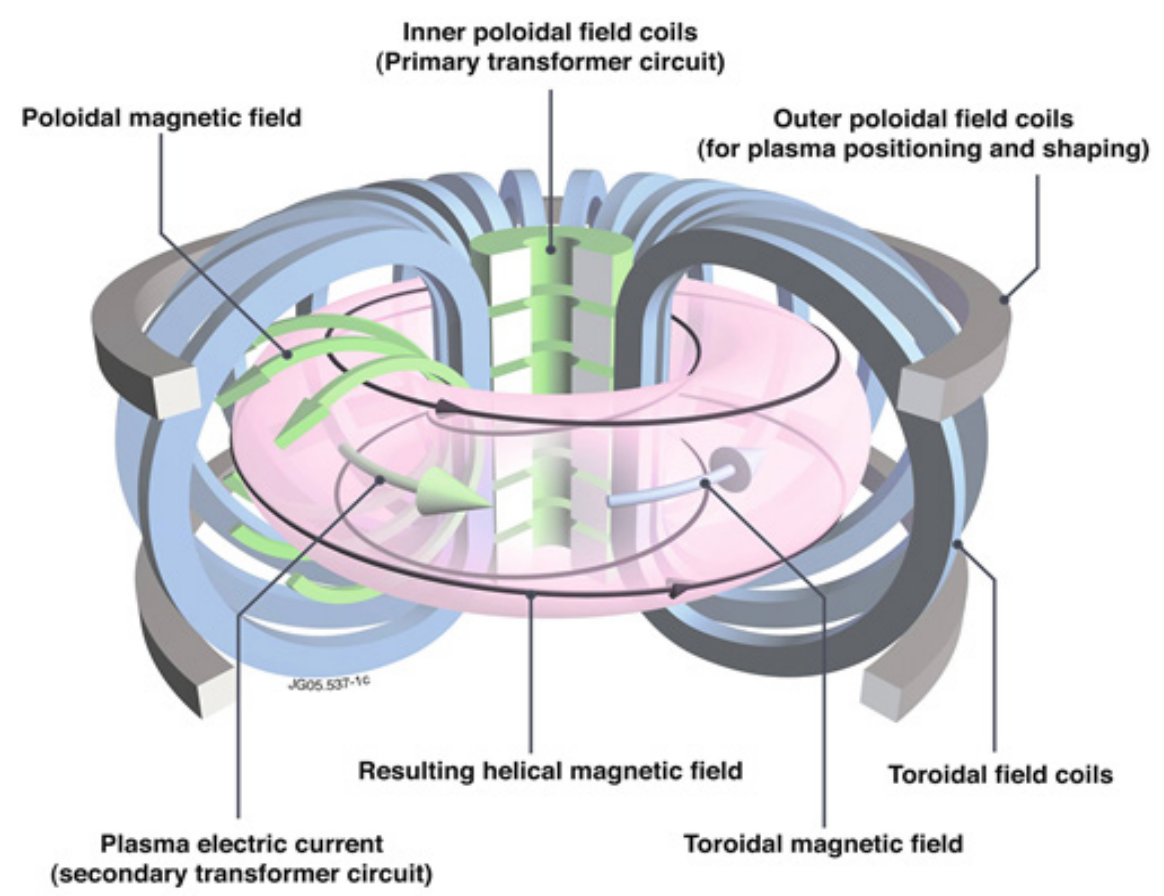

While tokamaks show great potential, there are many hurdles associated with the technology. These problems not only affect the confinement of the plasma; they also affect the stability of the plasma. The viability of this technology is under debate $[39,40]$, as while these generators have been tested since the 1950's [41, 42], a fully functional reactor, that being one that can sustain an economically viable amount of energy production, has never been successfully built.

High confinement mode plasma (H-Mode) plasma is the most stable type of plasma [43, 44], while it has been achieved, it cannot be sustained for more than a few minutes at most in tokamak fusion devices [45]. H-mode is when magnetically contained plasma is heated until it goes from a state of low-containment (L-Mode) to H-Mode state and becomes more stable [46, 47]. This stability of the reaction is also what causes the plasma to destabilise as the fusion of hydrogen creates helium, which is heavier than hydrogen, and throws off the balance of the pressure in the chamber [48].

\section{Methods}

The meta study into the applicability of fusion reactors as a technology for energy generation was undertaken with the decision made that magnetic confinement fusion devices would be the main focus of our investigations.

The scientific databases used to search for reactors includes Scopus, ResearchGate, Google Scholar and Web of Science Core collection using keywords such as 'tokamak', 'fusion' and names of operational tokamaks found in preliminary research. The data collected only includes measured 
tokamak design parameters from papers on experimentally built tokamaks and excludes theoretical data. We did not discriminate devices based upon year in which they were built or published, however referenced background information was preferred to have been published within the past fifteen years.

To proceed with the research on the tokamak design parameters, the data was compiled into a spreadsheet and sorted based upon either spherical or toroidal plasma chamber designs. The parameters were then analysed to determine any correlations that could be found between them with particular emphasis on Plasma Current, Volume and applied magnetic field. A study into the significance of the vacuum chamber as a variable in other aspects of the design parameters was undertaken with the assumption that all devices had uniform geometry. The equations that follow illustrate what geometrical assumptions were made for toroidal and spherical geometries respectively.

$$
\begin{gathered}
V_{\text {Toroidal }}=\left(\pi a^{2}\right)\left(2 \pi R^{2}\right) \\
V_{\text {Spherical }}=\left(\frac{4}{3} \pi R^{3}\right)-\left(\pi a^{2}(2 R)\right)
\end{gathered}
$$

Where ' $\mathrm{R}$ ' and ' $\mathrm{a}$ ' are considered the major and minor radii respectively. All calculations were performed in Microsoft Office Excel 2016.

\section{Results}

\subsection{Toroidal and Spherical Tokamak data points}

The tokamak design parameters obtained are listed against their respective device in order of the calculated assumed volumes. Tabulated data has been included for selected parameters to increase the clarity of the results and to match said parameters with their respective device without reducing the visibility of the graphical results. Parameters listed include name of the tokamak fusion device, major device radius $\mathrm{R}$ measured in metres, minor device radius a measured in metres, toroidal magnetic field strength $\mathrm{B}_{\mathrm{T}}$ measured in Teslas, Plasma current IP measured in mega amperes and calculated assumed volume $\mathrm{V}$ in cubic metres. In addition to the data set listed below, additional parameters including fusion power, mean electron density and calculated aspect ratio were obtained how they have not been included as there were not analysed for the purpose of inclusion in this meta report. 
Table 1. Table volume, toroidal magnetic field and plasma current of Toroidal Tokamaks [49-72]

\begin{tabular}{|c|c|c|c|c|c|c|c|c|c|c|c|}
\hline Device & $\mathbf{R}(\mathbf{m})$ & $\mathbf{a}(\mathrm{m})$ & $\begin{array}{l}\mathbf{B}_{\mathbf{T}} \\
(\mathbf{T})\end{array}$ & $\begin{array}{l}\text { IP } \\
\text { (MA) }\end{array}$ & $V\left(\mathbf{m}^{3}\right)$ & Device & $\mathbf{R}(\mathbf{m})$ & $\mathbf{a}(\mathrm{m})$ & $\mathbf{B}_{\mathrm{T}}(\mathrm{T})$ & $\begin{array}{l}\text { IP } \\
\text { (MA) }\end{array}$ & $V\left(\mathbf{m}^{3}\right)$ \\
\hline GOLEM & 0.4 & 0.085 & 0.8 & 0.025 & 0.057046 & HT-7 & 1.22 & 0.29 & 2.5 & 0.25 & 2.025282 \\
\hline EGYPTOR & 0.3 & 0.1 & 1.2 & 0.1 & 0.059218 & EAST & 1.75 & 0.4 & 2 & 0.5 & 5.526978 \\
\hline ISTTOK & 0.46 & 0.085 & 0.6 & 0.1 & 0.065603 & TCV & 0.88 & 0.7 & 1.4 & 1.2 & 8.511547 \\
\hline STOR-M & 0.46 & 0.12 & 0.15 & 0.004 & 0.130753 & KSTAR & 1.8 & 0.5 & 3.5 & 2 & 8.882644 \\
\hline IR-T1 & 0.45 & 0.125 & 1 & 0.04 & 0.138791 & DIII-D & 1.74 & 0.56 & 1.9 & 1.1 & 10.77098 \\
\hline COMPASS & 0.56 & 0.21 & 2.1 & 0.4 & 0.48748 & ASDEX & 1.65 & 0.8 & 3.1 & 2 & 20.8446 \\
\hline $\begin{array}{l}\text { Alcator C- } \\
\text { Mod }\end{array}$ & 0.67 & 0.22 & 8.1 & 2 & 0.640103 & $\begin{array}{l}\text { Tore } \\
\text { Supra }\end{array}$ & 2.25 & 0.7 & 9 & 1.7 & 21.76248 \\
\hline SST-1 & 1.1 & 0.2 & 3 & 0.22 & 0.868525 & TFTR & 3.1 & 0.96 & 6 & 3 & 56.39413 \\
\hline ADITYA & 0.75 & 0.25 & 0.9 & 0.08 & 0.925275 & $\begin{array}{l}\text { UCLA- } \\
\text { ET }\end{array}$ & 5 & 1 & 0.25 & 0.045 & 98.69604 \\
\hline TEXT & 1.05 & 0.255 & 1.8 & 0.16 & 1.347719 & JET & 2.96 & 2.1 & 3.45 & 3.2 & 257.6677 \\
\hline
\end{tabular}

Table 2. Table volume, toroidal magnetic field and plasma current of Spherical Tokamaks [73-93]

\begin{tabular}{|c|c|c|c|c|c|c|c|c|c|c|c|}
\hline Device & $\mathbf{R}(\mathbf{m})$ & $\mathbf{a}(\mathrm{m})$ & $\mathbf{B}_{\mathrm{T}}(\mathrm{T})$ & $\begin{array}{l}\text { IP } \\
\text { (MA) }\end{array}$ & $V\left(m^{3}\right)$ & Device & $\begin{array}{l}R \\
(\mathbf{m})\end{array}$ & $a(m)$ & $\begin{array}{l}\mathbf{B}_{\mathbf{T}} \\
(\mathbf{T})\end{array}$ & $\begin{array}{l}\text { IP } \\
\text { (MA) }\end{array}$ & $V\left(m^{3}\right)$ \\
\hline $\begin{array}{l}\text { Medusa- } \\
\text { CR }\end{array}$ & 0.14 & 0.1 & 0.5 & 0.04 & 0.02029 & START & 0.32 & 0.26 & 0.4 & 0.25 & 0.273176 \\
\hline GUTTA & 0.16 & 0.084 & 1.5 & 0.15 & 0.024251 & $\begin{array}{l}\text { Globus- } \\
\text { M }\end{array}$ & 0.36 & 0.24 & 0.65 & 0.5 & 0.32572 \\
\hline GLAST & 0.2 & 0.1 & 0.4 & 0.05 & 0.046077 & UTST & 0.39 & 0.24375 & 0.3 & 0.31 & 0.394066 \\
\hline ST25 & 0.25 & 0.125 & 0.2 & 0.02 & 0.089994 & LTX & 0.4 & 0.27 & 0.4 & 0.4 & 0.4513 \\
\hline LATE & 0.25 & 0.2 & 0.12 & 0.004 & 0.128282 & FBX-II & 0.47 & 0.33 & 0.5 & 0.1 & 0.756485 \\
\hline ETE & 0.3 & 0.2 & 0.8 & 0.44 & 0.188496 & Pegasus & 0.45 & 0.375 & 0.18 & 0.3 & 0.779311 \\
\hline HIT & 0.3 & 0.2 & 0.46 & 0.15 & 0.188496 & QUEST & 0.68 & 0.4 & 0.25 & 0.02 & 2.0007 \\
\hline CPD & 0.3 & 0.2 & 0.3 & 0.15 & 0.188496 & КТМ & 0.9 & 0.45 & 1 & 0.75 & 4.198739 \\
\hline SUNIST & 0.3 & 0.23 & 1.15 & 0.05 & 0.212811 & $\begin{array}{l}\text { NSTX- } \\
\text { U }\end{array}$ & 0.934 & 0.6227 & 1 & 2 & 5.688485 \\
\hline
\end{tabular}

\subsection{Plasma current against toroidal magnetic field strength analysis}

Data points contained in the following series of graphs depict parameters listed in the above tables for each respective tokamak fusion device. 

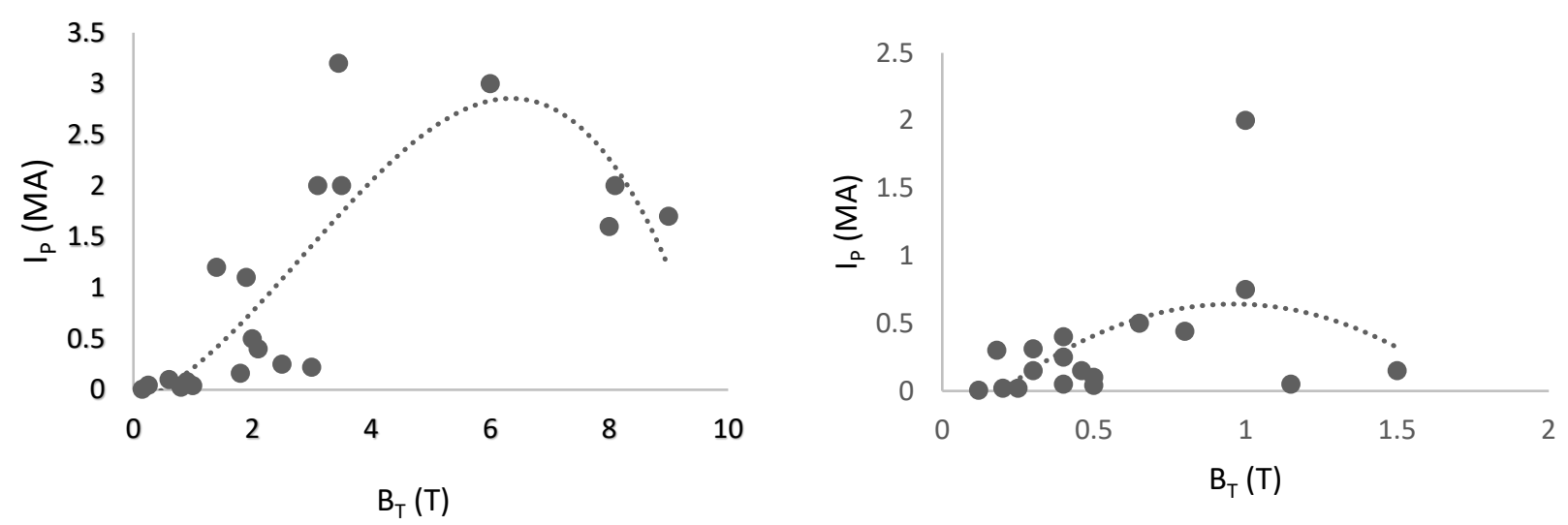

Figure 3. Plasma Current $\left(I_{P}\right)$ vs Toroidal Magnetic field $\left(B_{T}\right)$ where the Plasma current is measured in mega Amps (MA) and magnetic field in Teslas (T). Graph 3a, which is on the right, is based on conventional tokamaks whereas $3 b$, which is on the left, is based on spherical tokamaks. The outlier in $3 b$ is NSTX-U with an IP of $2 M A$.

\subsection{Volume against plasma current analysis}
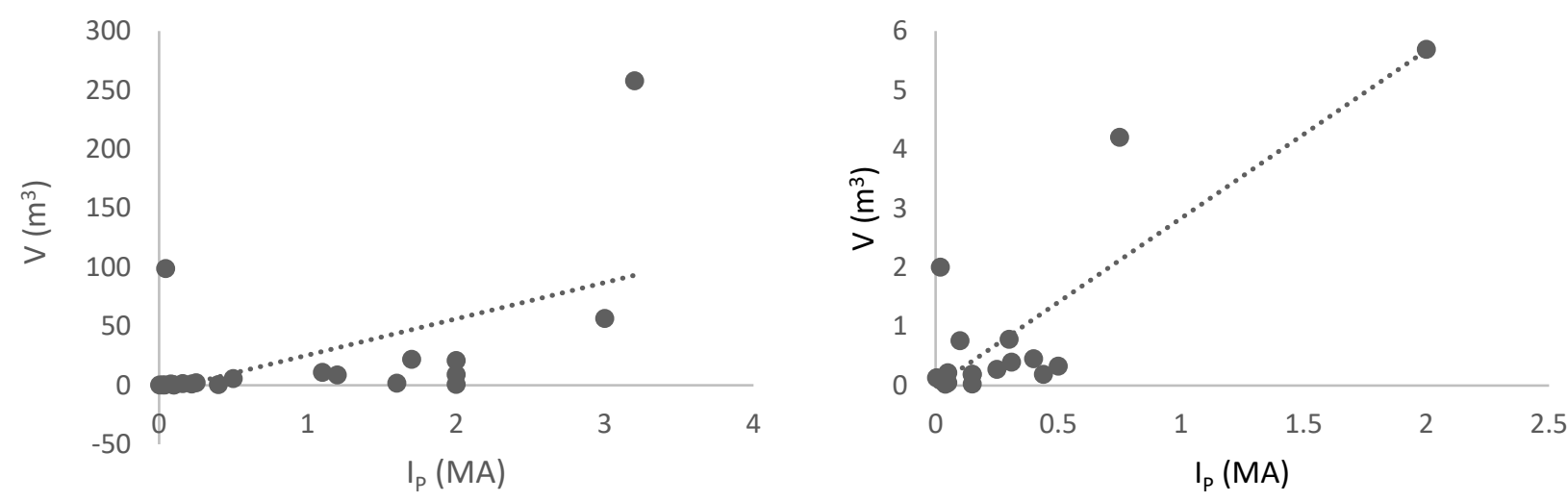

Figure 4. Toroidal Tokamak Volume vs Plasma current with $I_{P}$ in $(M A)$ and V in $\left(\mathrm{m}^{3}\right)$. Graph 4a, which is on the right, is based on conventional tokamaks whereas $4 b$, which is on the left, is based on spherical tokamaks. The outliers for 4 a are UCLA-ET with an IP of 0.045MA and a volume of $98.7 \mathrm{~m}^{3}$.

\section{Discussion}

The tokamak machine radius parameters for often varied between journal articles by around $\pm 0.05 \mathrm{~m}$, this increases the uncertainty in our volume assumptions however based on the variety of results any observed trends should only be affected by a negligible amount. In addition to the assumption that all geometries of both spherical and toroidal geometries are the same throughout their respective machine type designs, the assumption was also applied that any inserts or technology differences such as Langmuir probes or variances in materials used for the chamber coating or heat shield.

In addition to the varying measurements, data on the tokamaks often had to be taken from more than one paper as the required parameters were not always reported from a singular source.

Additionally, it should be noted that spherical tokamaks have not been practically researched to the same degree as traditional torus shaped designs, this is not represented in our research as we have 
obtained an amount of data on the parameters of spherical designs that is similar to the torus tokamak data obtained. Furthermore, the data used is not indicative of the parameters of the machines at the present but it only an indication as to the parameters of the machine used in the research papers listed, this means that any changes to the parameters over time are not represented in our analysis but could be the subject of further research.

During the fusion reaction in the tokamaks, there is an increasing change in enthalpy as the hydrogen is converted to helium and neutral beams, or electron cyclotron heating, increase the speed and temperature of the reaction which also increases the density and pressure. The reaction speed is also increased by the magnetic field coils as the current in the magnetic coils is increased until it reaches a maximum [94]. The variation between the time taken for the tokamaks to reach the maximum coil current is dependent on each tokamak design parameters and varies between them.

\subsection{Plasma current and toroidal magnetic field}

\subsubsection{Conventional tokamak}

The trend suggested Figure 3a shows a possible parabolic relationship between the plasma current and the magnetic field, with a maximum magnetic field turning point around 6 Tesla's with an equivalent current of $3 \mathrm{MA}$. This correlates with the theoretical aspect of plasma physics in which to maintain the plasma current, it operates in pulse mode until the poloidal coils reach their maximum current. When the maximum current is reached, induction of the plasma current ceases. To increase the current induction efficiency for conventional tokamaks, superconducting coils are used, as seen in the Tore Supra [32] which has a $\mathrm{B}_{\mathrm{T}}$ of $9 \mathrm{~T}$.

\subsubsection{Spherical tokamak}

The tighter magnetic field of spherical tokamaks compared to conventional tokamaks seem to point to an outcome that spherical tokamaks can achieve a higher plasma pressure. This is seen in Figure $3 \mathrm{~b}$ where the spherical magnetic field range of the coils is between $0.12-1.5 \mathrm{~T}$, whereas in comparison to the conventional tokamak in Figure 3a, the toroidal magnetic field range is between 0.15-9T.

However, the outlying plasma current factor tokamak NSTX-U does not follow the trend as it has a plasma current of $2 \mathrm{MA}$ which is greater than the more frequently observed values of plasma current strength in spherical tokamaks. This could potentially be because the NSTX-U has a greater volume and can therefore allow for a greater plasma current.

\subsection{Plasma current and volume}

\subsubsection{Conventional tokamaks}

Torus shaped tokamaks have a larger area from their inherent shape, than a spherical tokamak. As seen in figure $4 \mathrm{a}$, the increase in plasma current for volume is linear. The equation for this is $y=30.729 x-5.173$, hence the increase is measurable at about 30 cubic meters for every Mega Ampere. 
For this reason, it is recommended that future generation tokamaks be larger size to for a larger desired plasma current output.

The exception to this being the UCLA-ET, with the second largest measured volume of currently operational Tokamak. Although it has a large volume of $98.7 \mathrm{~m}^{3}$, due to parameters such as its weaker magnetic field strength of 0.25T, UCLA-ET has a lower induced plasma current of 0.045MA. JET however, is the world's largest tokamak for its volume as seen in the upper right corner of figure 4a, is a perfect example of proportionality expected with volume and plasma current.

\subsubsection{Spherical tokamak}

Spherical tokamaks are designed to operate using smaller chamber volumes. Since the coils need to be cooled to maintain efficiency, if the volume is too large, the coils will not be cooled sufficiently as they pass through the narrow core and the plasma current will not be maintained well due to decreased efficiency of the magnetic coils. In figure $4 b$, the volumes are between $0.2-5.7 \mathrm{~m}^{3}$ which differ greatly to conventional tokamaks which range between $0.13-258 \mathrm{~m}^{3}$. Although the relationship seems linear, that is due to the lower volumes used for the spherical tokamaks. Increasing the volume further than what has been shown in figure $4 \mathrm{~b}$ will likely show a curved graph with the gradient decreasing until it reaches a point where the heat affecting the coils passing through the narrow core is too great and the combined magnetic fields are no longer at angle to maintain the motion of the plasma inside the reactor, inhibiting the reactor's operation.

The points on the graph that appear to be outliers are not deemed as outliers as the parameters per tokamak differ, affecting the plasma current induction and maintenance. Not all the parameters that affect the plasma current are mentioned in the tables above, such as the temperature of the system. Another point to be noted is due to the vast difference in range between spherical and conventional tokamaks, the graph points for spherical tokamaks will appear to have greater variance than what is expected. It would be recommended to accommodate for the overheating of the coils in order to manage spherical tokamaks with larger volumes.

\section{Conclusion}

Energy generation via the use of nuclear technology has been a triumph of modern science however fusion based nuclear power from tokamak reactors has not yet been accomplished with any large scale practical application outside scientific research. There is a trend of spherical tokamak fusion devices to be developed with small scale operating parameters. Tokamaks of the traditional torus design have a peak in their ability to generate plasma current as the size increases, supporting the argument that toroidal tokamaks are not limited by volume whereas spherical have a potential volume limit. Further scientific engineering needs to be developed further upon before tokamak devices will be a viable technology to be used for energy generation. 


\section{Acknowledgments}

Thank you to Dr Jurgen Schulte, Blake Regan and Liam Martin, as well as our peers for your support and advice in producing our first paper.

\section{References}

1. Lawson JD. Some criteria for a power producing thermonuclear reactor. Proceedings of the Physical Society. Section B. 1957;70(1):6. doi: https://doi.org/10.1088/0370-1301/70/1/303

2. Stacey Jr WM, Abdou MA, Brooks JN. Tokamak experimental power reactor. InFusion reactor design concepts 1978.

3. Momirlan M, Veziroglu TN. The properties of hydrogen as fuel tomorrow in sustainable energy system for a cleaner planet. International journal of hydrogen energy. $2005 \mathrm{Jul}$ 31;30(7):795-802. doi: https://doi.org/10.1016/j.ijhydene.2004.10.011

4. SUCH, T.P.P., 2006. Materials needs for fusion.

5. Pralogki T, Onjun T, Poolyarat N, Picha R. Impurity transport simulation in ITER Tokamak.

6. Kawasaki K, Hatakeyama T. Coil malfunction protection system for TOKAMAK type thermonuclear device.

7. Takashima T, Ohta M, Shimizu M. Drive characteristics of a fast movable limiter in the JT-60 tokamak. Review of Scientific Instruments. 1978 Feb;49(2):194-9. doi: https://doi.org/10.1063/1.1135381

8. Braams CM, Stott PE. Nuclear Fusion: half a century of magnetic confinement research. Plasma Physics and Controlled Fusion. 2002 Aug 21;44(8):1767. doi: https://doi.org/10.1088/0741$\underline{3335 / 44 / 8 / 701}$

9. Moses, E.I., 2009. Ignition on the National Ignition Facility: a path towards inertial fusion energy. Nuclear Fusion, 49(10), p.104022. doi: https://doi.org/10.1088/0029-5515/49/10/104022

10. Petrov YV. Muon catalysis for energy production by nuclear fusion. Nature. 1980 Jun 12;285(5765):466-8. doi: https://doi.org/10.1038/285466a0

11. Focardi S, Rossi A. A new energy source from nuclear fusion. Journal of Nuclear Physics, http://www. journal-of-nuclearphysics. com. 2010 Mar 22.

12. Brody RA. Some systemic effects of the spread of nuclear weapons technology: a study through simulation of a multi-nuclear future. Journal of Conflict Resolution. 1963 Dec 1;7(4):663-7. doi: https://doi.org/10.1177/002200276300700401

13. Holloway D. Research note: Soviet thermonuclear development. International Security. 1979;4(3):192-7. doi: https://doi.org/10.2307/2626701 
14. Bondarenko BD. Role played by OA Lavrent'ev in the formulation of the problem and the initiation of research into controlled nuclear fusion in the USSR. Physics-Uspekhi. 2001;44(8):84451. doi: https://doi.org/10.1070/PU2001v044n08ABEH000910

15. Vukolov KY, Guseva MI, Evstigneev SA, Medvedev AA, Zvonkov SN. Exposure of stainless steel mirrors in T-10 tokamak. Plasma Devices and Operations. 2004 Sep 1;12(3):193-202. doi:https://doi.org/10.1080/1051999042000238040

16. Isei N, Sato M, Tsuzuki K, Kawashima H, Miura Y, Kimura H. Application of low activation ferritic steel in the JFT-2M tokamak: Evaluation of magnetic effect on the plasma. Fusion technology. 2001;39(2):1101-5.

17. Piatti G, Matteazzi S, Petrone G. Time independent tensile behaviour of a high manganese steel selected as a candidate material in conceptual tokamak fusion reactor designs. Nuclear engineering and design. Fusion. 1985 Jan 1;2(3):391-406. doi: $\quad$ https://doi.org/10.1016/0167$\underline{899 X(85) 90027-8}$

18. Molfino P, Repetto M. Comparison of different strategies for the analysis of nonlinear coupled thermo-magnetic problems under pulsed conditions (application to Tokamak coils). IEEE Transactions on Magnetics. 1990 Mar;26(2):559-62. doi: https://doi.org/10.1109/20.106378

19. Okabayashi M, Bialek J, Bondeson A, Chance MS, Chu MS, Garofalo AM, Hatcher R, In Y, Jackson GL, Jayakumar RJ, Jensen TH. Control of the resistive wall mode with internal coils in the DIII-D tokamak. Nuclear fusion. 2005 Nov 29;45(12):1715. doi: https://doi.org/10.1088/0029$\underline{5515 / 45 / 12 / 028}$

20. Kustom RL, Fuja R, Smith RP, DeOlivares J, Kellman A, Bauer TJ. The Use of Multiphase Inductor-Converter Bridges as Actively-Controlled Power Supplies for Tokamak Coils. Argonne Rational Laboratory Report AHL/FPP/TH-78 (April 11, 1977). 1977.

21. Buzhinskij OI, Semenets YM. Thick boron carbide coatings for protection of tokamak first wall and divertor. Fusion Engineering and design. 1999 Aug 31;45(4):343-60. doi: https://doi.org/10.1016/S0920-3796(99)00007-1

22. Bell MG, Kugel H, Mansfield D, Kaita R, Gerhardt S, Paul S, Bell RE, Maingi R, Canik J. Plasma Response to Lithium-Coated Plasma-Facing Components in NSTX. Bulletin of the American Physical Society. 2009 Nov 3;54.

23. Wu Y, FDS Team. Design status and development strategy of China liquid lithium-lead blankets and related material technology. Journal of Nuclear Materials. 2007 Aug 1;367:1410-5. doi: https://doi.org/10.1016/j.jnucmat.2007.04.031

24. JET Team, 1992. Fusion energy production from a deuterium-tritium plasma in the JET tokamak. Nuclear Fusion, 32(2), p.187. doi: https://doi.org/10.1088/0029-5515/32/2/I01

25. McGuire KM, Adler H, Alling P, Ancher C, Anderson H, Anderson JL, Anderson JW, Arunasalam $\mathrm{V}$, Ascione G, Ashcroft D, Barnes CW. Review of deuterium-tritium results from the Tokamak 96 
Fusion Test Reactor. Physics of Plasmas. 1995 Jun;2(6):2176-88. doi:

https://doi.org/10.1063/1.871303

26. Taylor G, Strachan JD, Budny RV, Ernst DR. Fusion heating in a deuterium-tritium tokamak plasma. Physical review letters. 1996 Apr 8;76(15):2722. doi:

https://doi.org/10.1103/PhysRevLett.76.2722

27. Goldston RJ, McCune DC, Towner HH, Davis SL, Hawryluk RJ, Schmidt GL. New techniques for calculating heat and particle source rates due to neutral beam injection in axisymmetric tokamaks. Journal of computational physics. 1981 Sep 1;43(1):61-78. doi: https://doi.org/10.1016/00219991(81)90111-X

28. Kaye SM, Bell MG, Bol K, Boyd D, Brau K, Buchenauer D, Budny R, Cavallo A, Couture P, Crowley T, Darrow DS. Attainment of high confinement in neutral beam heated divertor discharges in the PDX tokamak. Journal of nuclear Materials. 1984 May 1;121:115-25. doi: https://doi.org/10.1016/0022-3115(84)90111-9

29. Jassby DL. Neutral-beam-driven tokamak fusion reactors. Nuclear Fusion. 1977 Apr;17(2):309. doi: https://doi.org/10.1088/0029-5515/17/2/015

30. Forest CB, Hwang YS, Ono M, Greene G, Jones T, Choe W, Schaffer M, Hyatt A, Osborne T, Pinsker RI, Petty CC. Investigation of the formation of a fully pressure-driven tokamak. Physics of plasmas. 1994 May;1(5):1568-75. doi: https://doi.org/10.1063/1.870708

31. Jones SE, Palmer EP, Czirr JB, Decker DL, Jensen GL, Thorne JM, Taylor SF, Rafelski J. Observation of cold nuclear fusion in condensed matter. Nature. 1989 Apr 27;338(6218):737-40. doi: https://doi.org/10.1038/338737a0

32. Glendenning NK. Compact stars: Nuclear physics, particle physics and general relativity. Springer Science \& Business Media; 2012 Dec 6.

33. Buzhinskij OI, Semenets YM. Thick boron carbide coatings for protection of tokamak first wall and divertor. Fusion Engineering and design. 1999 Aug 31;45(4):343-60. doi: https://doi.org/10.1016/S0920-3796(99)00007-1

34. Matsukawa M. Engineering feature in the design of JT-60SA. 2006.

35. Gryaznevich M, Svoboda V, Stockel J, Sykes A, Sykes N, Kingham D, Hammond G, Apte P, Todd TN, Ball S, Chappell S. Progress in application of high temperature superconductor in tokamak magnets. Fusion Engineering and Design. 2013 Oct 31;88(9):1593-6. doi: https://doi.org/10.1016/j.fusengdes.2013.01.101

36. Bromberg L, Tekula M, El-Guebaly LA, Miller R, ARIES Team. Options for the use of high temperature superconductor in tokamak fusion reactor designs. Fusion Engineering and Design. 2001 Feb 28;54(2):167-80. doi: https://doi.org/10.1016/S0920-3796(00)00432-4

37. Whyte DG, Jernigan TC, Humphreys DA, Hyatt AW, Lasnier CJ, Parks PB, Evans TE, Rosenbluth MN, Taylor PL, Kellman AG, Gray DS. Mitigation of tokamak disruptions using high-pressure gas 
injection. Physical review letters. 2002 Jul 12;89(5):055001. doi:

https://doi.org/10.1103/PhysRevLett.89.055001

38. Dubois MA, Pecquet AL, Reverdin C. Internal disruptions in the TFR tokamak: a phenomenological analysis. Nuclear Fusion. 1983 Feb;23(2):147. doi: https://doi.org/10.1088/0029$\underline{5515 / 23 / 2 / 002}$

39. Manheimer W. Hybrid fusion: The only viable development path for tokamaks?. Journal of fusion energy. 2009 Mar 1;28(1):60-82. doi: https://doi.org/10.1007/s10894-008-9156-Z

40. Hender TC, Knight PJ, Cook I. Key issues for the economic viability of magnetic fusion power. Fusion Technology. 1996 Dec 1;30(3):1605-12.

41. Lawson JD. Some criteria for a power producing thermonuclear reactor. Proceedings of the Physical Society. Section B. 1957;70(1):6. doi: https://doi.org/10.1088/0370-1301/70/1/303

42. Smirnov VP. Tokamak foundation in USSR/Russia 1950-1990. Nuclear Fusion. 2009 Dec 30;50(1):014003. doi: https://doi.org/10.1088/0029-5515/50/1/014003

43. Itoh SI, Itoh K. Model of L to H-mode transition in Tokamak. Physical review letters. 1988 May 30;60(22):2276. doi: https://doi.org/10.1103/PhysRevLett.60.2276

44. Kim J, Burrell KH, Gohil P, Groebner RJ, Kim YB, John HS, Seraydarian RP, Wade MR. Rotation characteristics of main ions and impurity ions in H-mode tokamak plasma. Physical review letters. 1994 Apr 4;72(14):2199. doi: https://doi.org/10.1103/PhysRevLett.72.2199

45. Mutoh T, Kumazawa R, Tetsuo SE, Saito K, Nakamura Y, Shin KU, Takeiri Y, Shimozuma T, Yoshimura Y, Igami H, Ohkubo K. Thirty-minute plasma sustainment by ICRF, EC and NBI heating in the large helical device. Journal of Plasma and Fusion Research. 2005;81(4):229-30. doi: https://doi.org/10.1585/jspf.81.229

46. Burrell KH, Carlstrom TN, Doyle EJ, Finkenthal D, Gohil P, Groebner RJ, Hillis DL, Kim J, Matsumoto H, Moyer RA, Osborne TH. Physics of the L-mode to H-mode transition in tokamaks. Plasma Physics and Controlled Fusion. 1992 Dec;34(13):1859. doi: https://doi.org/10.1088/0741$\underline{3335 / 34 / 13 / 014}$

47. Itoh SI, Itoh K. Model of L to H-mode transition in Tokamak. Physical review letters. 1988 May 30;60(22):2276. doi: https://doi.org/10.1103/PhysRevLett.60.2276

48. Reiter D, Kever H, Wolf GH, Baelmans M, Behrisch R, Schneider R. Helium removal from tokamaks. Plasma Physics and Controlled Fusion. 1991 Nov;33(13):1579. doi: https://doi.org/10.1088/0741-3335/33/13/008

49. Adamek J, Seidl J, Komm M, Weinzettl V, Panek R, Stockel J, et al. Fast measurements of the electron temperature and parallel heat flux in ELMy H-mode on the COMPASS tokamak. Nuclear Fusion. 2017;57(2). doi: https://doi.org/10.1088/0029-5515/57/2/022010 
50. Anton M, Weisen H, Dutch MJ, vonderLinden W, Buhlmann F, Chavan R, et al. X-ray tomography on the TCV tokamak. Plasma Phys Control Fusion. 1996;38(11):1849-78. doi: https://doi.org/10.1088/0741-3335/38/11/001

51. Bhatt SB, Bora D, Buch BN, Gupta CN, Jain KK, Jha R, et al. ADITYA - THE 1ST INDIAN TOKAMAK. Indian Journal of Pure \& Applied Physics. 1989;27(9-10):710-42.

52. Cabral JAC, Varandas CAF, Alonso MP, Belo P, Canario R, Fernandes H, et al. Enhancement of the ISTTOK plasma confinement and stability by negative limiter biasing. Plasma Phys Control Fusion. 1998;40(6):1001-19. doi: https://doi.org/10.1088/0741-3335/40/6/008

53. Diamond PH, Itoh SI, Itoh K, Hahm TS. Zonal flows in plasma - a review. Plasma Phys Control Fusion. 2005;47(5):R35-R161. doi: https://doi.org/10.1088/0741-3335/47/5/R01

54. Dimits AM, Bateman G, Beer MA, Cohen BI, Dorland W, Hammett GW, et al. Comparisons and physics basis of tokamak transport models and turbulence simulations. Physics of Plasmas. 2000;7(3):969-83. doi: https://doi.org/10.1063/1.873896

55. El Sisi AB, Hegazy H. EGYPTOR tokamak: Modification of the original design using permanent compensation coils and first results of the breakdown discharge. Journal of Fusion Energy. 2003;22(3):191-4. doi: https://doi.org/10.1023/B:JOFE.0000037786.26421.da

56. Fitzpatrick R. HELICAL TEMPERATURE PERTURBATIONS ASSOCIATED WITH TEARING MODES IN TOKAMAK PLASMAS. Physics of Plasmas. 1995;2(3):825-38. doi: https://doi.org/10.1063/1.871434

57. Ghendrih P, Grosman A, Capes H. Theoretical and experimental investigations of stochastic boundaries in tokamaks. Plasma Phys Control Fusion. 1996;38(10):1653-724. doi: https://doi.org/10.1088/0741-3335/38/10/002

58. Hutchinson IH, Boivin R, Bombarda F, Bonoli P, Fairfax S, Fiore C, et al. 1ST RESULTS FROM ALCATOR-C-MOD. Physics of Plasmas. 1994;1(5):1511-8. doi: https://doi.org/10.1063/1.870701

59. Joseph BK, Jha R, Kaw PK, Mattoo SK, Rao CVS, Saxena YC. Observation of vortex-like coherent structures in the edge plasma of the ADITYA tokamak. Physics of Plasmas. 1997;4(12):4292-300. doi: https://doi.org/10.1063/1.872611

60. Lee GS, Kim J, Hwang SM, Chang CS, Chang HY, Cho MH, et al. The KSTAR project: An advanced steady state superconducting tokamak experiment. Nuclear Fusion. 2000;40(3Y):575-82. doi: https://doi.org/10.1088/0029-5515/40/3Y/319

61. Levinton FM, Zarnstorff MC, Batha SH, Bell M, Bell RE, Budny RV, et al. IMPROVED CONFINEMENT WITH REVERSED MAGNETIC SHEAR IN TFTR. Physical Review Letters. 1995;75(24):4417-20. doi: https://doi.org/10.1103/PhysRevLett.75.4417

62. Liang Y, Koslowski HR, Thomas PR, Nardon E, Alper B, Andrew P, et al. Active control of type-I edge-localized modes with $n=1$ perturbation fields in the JET tokamak. Physical Review Letters. 2007;98(26). doi: https://doi.org/10.1103/PhysRevLett.98.265004 
63. Rhodes TL, Peebles WA, Doyle EJ. THE UCLA FREQUENCY TUNABLE CORRELATION REFLECTOMETER SYSTEM ON DIII-D. Review of Scientific Instruments. 1992;63(10):4661-4. doi: https://doi.org/10.1063/1.1143655

64. Ritz CP, Bengtson RD, Levinson SJ, Powers EJ. TURBULENT STRUCTURE IN THE EDGE PLASMA OF THE TEXT TOKAMAK. Physics of Fluids. 1984;27(12):2956-9. doi: https://doi.org/10.1063/1.864611

65. Saxena YC, Team SST. Present status of the SST-1 project. Nuclear Fusion. 2000;40(6):1069-82. doi: https://doi.org/10.1088/0029-5515/40/6/305

66. Sen S, Xiao C, Hirose A, Cairns RA. Role of parallel flow in the improved mode on the STOR-M tokamak. Physical Review Letters. 2002;88(18). doi:

https://doi.org/10.1103/PhysRevLett.88.185001

67. Svoboda V, Huang B, Mlynar J, Pokol GI, Stockel J, Vondrasek G. Multi-mode remote participation on the GOLEM tokamak. Fusion Engineering and Design. 2011;86(6-8):1310-4. doi: https://doi.org/10.1016/i.fusengdes.2011.02.069

68. Varandas CAF, Cabral JAC, Mendonca JT, Alonso MP, Amorim P, Carvalho BB, et al. Engineering aspects of the tokamak ISTTOK. Fusion Technology. 1996;29(1):105-15.

69. Vertkov A, Lyublinski I, Zharkov M, Mazzitelli G, Apicella ML, Iafrati M. Liquid tin limiter for FTU tokamak. Fusion Engineering and Design. 2017;117:130-4. doi:

https://doi.org/10.1016/j.fusengdes.2017.01.041

70. Wan BN, Teams EH-, Int C. Recent experiments in the EAST and HT-7 superconducting tokamaks. Nuclear Fusion. 2009;49(10). doi: https://doi.org/10.1088/0029-5515/49/10/104011

71. Wan YX, Team HT, Team H-U. Overview of steady state operation of HT-7 and present status of the HT-7U project. Nuclear Fusion. 2000;40(6):1057-68. doi: https://doi.org/10.1088/0029$\underline{5515 / 40 / 6 / 304}$

72. Wu Y. Conceptual design and testing strategy of a dual functional lithium-lead test blanket module in ITER and EAST. Nuclear Fusion. 2007;47(11):1533-9. doi: https://doi.org/10.1088/0029$\underline{5515 / 47 / 11 / 015}$

73. Berni LA, Albuquerque BFC. Stray light analysis for the Thomson scattering diagnostic of the ETE Tokamak. Review of Scientific Instruments. 2010;81(12). doi:

https://doi.org/10.1063/1.3505485

74. Carreras BA. Progress in anomalous transport research in toroidal magnetic confinement devices. Ieee Transactions on Plasma Science. 1997;25(6):1281-321. doi: https://doi.org/10.1109/27.650902

75. Guttenfelder W, Candy J, Kaye SM, Nevins WM, Wang E, Zhang J, et al. Simulation of microtearing turbulence in national spherical torus experiment. Physics of Plasmas. 2012;19(5). doi: https://doi.org/10.1063/1.3694104 
76. Hirooka Y, Zushi H, Bhattacharyay R, Sakamoto M, Idei H, Yoshinaga T, et al. Active particle control in the CPD compact spherical tokamak by a lithium-gettered rotating drum limiter. Journal of Nuclear Materials. 2009;390-91:502-6. doi: https://doi.org/10.1016/j.jnucmat.2009.01.060

77. Iblyaminova AD, Avdeeva GF, Aruev PN, Bakharev NN, Gusev VK, Zabrodsky VV, et al. Investigation of the plasma radiation power in the Globus-M tokamak by means of SPD silicon photodiodes. Plasma Physics Reports. 2016;42(10):909-18. doi:

https://doi.org/10.1134/S1063780X16100044

78. Inomoto M, Watanabe TG, Gi K, Yamasaki K, Kamio S, Imazawa R, et al. Centre-solenoid-free merging start-up of spherical tokamak plasmas in UTST. Nuclear Fusion. 2015;55(3). doi: https://doi.org/10.1088/0029-5515/55/3/033013

79. Irie M, editor Dielectric breakdown and tokamak start-up with FBX spherical torus. IEEE Conference Record - Abstracts 1996 IEEE International Conference on Plasma Science; 1996 3-5 June 1996.

80. Itoh S, Sato KN, Nakamura K, Zushi H, Sakamoto M, Hanada K, et al. Recent progress on high performance steady state plasmas in the superconducting tokamak TRIAM-1M. Nuclear Fusion. 1999;39(9Y):1257-70. doi: https://doi.org/10.1088/0029-5515/39/9Y/304

81. Lyublinski I, Vertkov A, Evtikhin V, Balakirev V, Ionov D, Zharkov M, et al. Module of lithium divertor for KTM tokamak. Fusion Engineering and Design. 2012;87(10):1719-23. doi: https://doi.org/10.1016/j.fusengdes.2011.07.012

82. Lyublinski IE, Vertkov AV. Experience and technical issues of liquid lithium application as plasma facing material in tokamaks. Fusion Engineering and Design. 2010;85(6):924-9. doi:

\section{https://doi.org/10.1016/j.fusengdes.2010.08.036}

83. McClements KG, Fredrickson ED. Energetic particles in spherical tokamak plasmas. Plasma Phys Control Fusion. 2017;59(5).

84. Menard JE, Gerhardt S, Bell M, Bialek J, Brooks A, Canik J, et al. Overview of the physics and engineering design of NSTX upgrade. Nuclear Fusion. 2012;52(8). doi: https://doi.org/10.1088/0029-5515/52/8/083015

85. Ono M, Bell MG, Bell RE, Bigelow T, Bitter M, Blanchard W, et al. Progress towards highperformance, steady-state spherical torus. Plasma Phys Control Fusion. 2003;45:A335-A50. doi: https://doi.org/10.1088/0741-3335/45/12A/022

86. Ovsyannikov DA, Ovsyannikov AD, Zhabko AP, Veremey EI, Vorobyov GM, Zavadskij VM. Program for scientific and educational investigations on the base of small spherical tokamak Gutta. Fradkov AL, Churilov AN, editors2005. 75-9 p. doi: https://doi.org/10.1109/phycon.2005.1513954

87. Qayyum A, Ahmad S, Ahmad N, Deeba F, Hussain S. Triple Probe Measurements in Transient Plasma of Pulsed Capacitive Discharge. Journal of Fusion Energy. 2015;34(2):405-10. doi: 
88. Qayyum A, Ahmad S, Khan R, Hussain S, Deeba F, Javed M, et al. Triple-probe Diagnostic Measurements in Plasma of GLAST Spherical Tokamak. Journal of Fusion Energy. 2016;35(2):205-13. doi: https://doi.org/10.1007/s10894-015-0010-9

89. Redd AJ, Nelson BA, Jarboe TR, Gu P, Raman R, Smith RJ, et al. Current drive experiments in the helicity injected torus (HIT-II). Physics of Plasmas. 2002;9(5):2006-13. doi: https://doi.org/10.1063/1.1448832

90. Sharapov SE, Alper B, Berk HL, Borba DN, Breizman BN, Challis CD, et al. Alfven wave cascades in a tokamak. Physics of Plasmas. 2002;9(5):2027-36. doi:

\section{https://doi.org/10.1063/1.1448346}

91. Soukhanovskii VA, Maingi R, Gates DA, Menard JE, Paul SF, Raman R, et al. Divertor heat flux mitigation in high-performance H-mode discharges in the National Spherical Torus Experiment. Nuclear Fusion. 2009;49(9). doi: https://doi.org/10.1088/0029-5515/49/9/095025

92. Tashima S, Zushi H, Isobe M, Hanada K, Idei H, Nakamura K, et al. Role of energetic electrons during current ramp-up and production of high poloidal beta plasma in non-inductive current drive on QUEST. Nuclear Fusion. 2014;54(2). doi: https://doi.org/10.1088/0029-5515/54/2/023010

93. Vorobyov GM, Ovsyannikov DA, Ovsyannikov AD, Suhov EV, Veremey EI, Zavadsky VM, et al., editors. The experiments of the small spherical tokamak Gutta. 16th IAEA Technical Meeting on Research Using Small Fusion Devices; 2005 Nov 30-Dec 03; Mexico City, MEXICO2006.

94. White RB. Theory of Tokamak Plasmas: Elsevier Science; 2017. 